\title{
Emission intensity readout of ion-selective electrodes operating under electrochemical trigger
}

\author{
Katarzyna Węgrzyn, Justyna Kalisz, Emilia Stelmach, Krzysztof Maksymiuk, \\ Agata Michalska \\ Faculty of Chemistry, University of Warsaw, Pasteura 1, 02-093 Warsaw, Poland \\ *agatam@chem.uw.edu.pl, +48 225622331
}

\section{Table of Content}

1. Scheme of electrode used

2. Emission spectra of FE-ISE membrane recorded in open circuit, as well as while applying oxidizing or reducing potential

3. Chronoamperometric dependencies corresponding to emission spectra presented above applying oxidizing or reducing potential to FE-ISE membrane sensor.

4. Chronopotentiometric studies and impedance spectra of FE-ISE membranes applied on glassy carbon or carbon paper substrate,

5. Effect of interfering ions presence on cyclic voltammograms and emission changes recorded for FE-ISE 


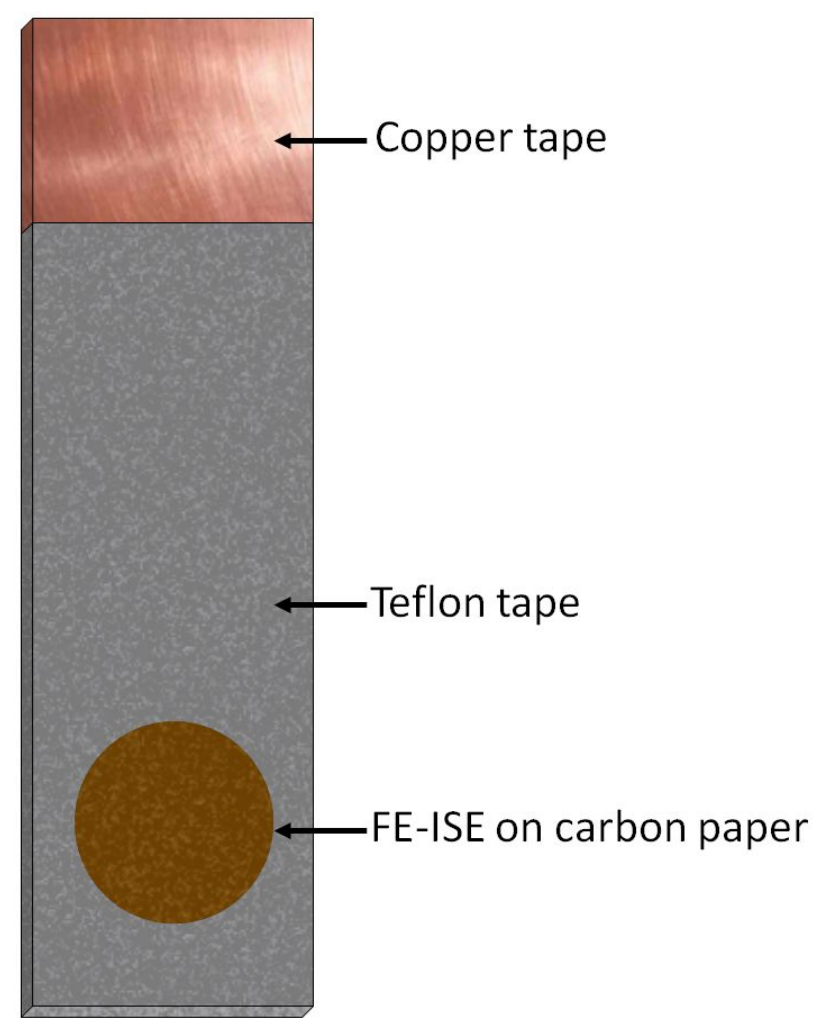

Figure S1. Scheme of electrode used. 


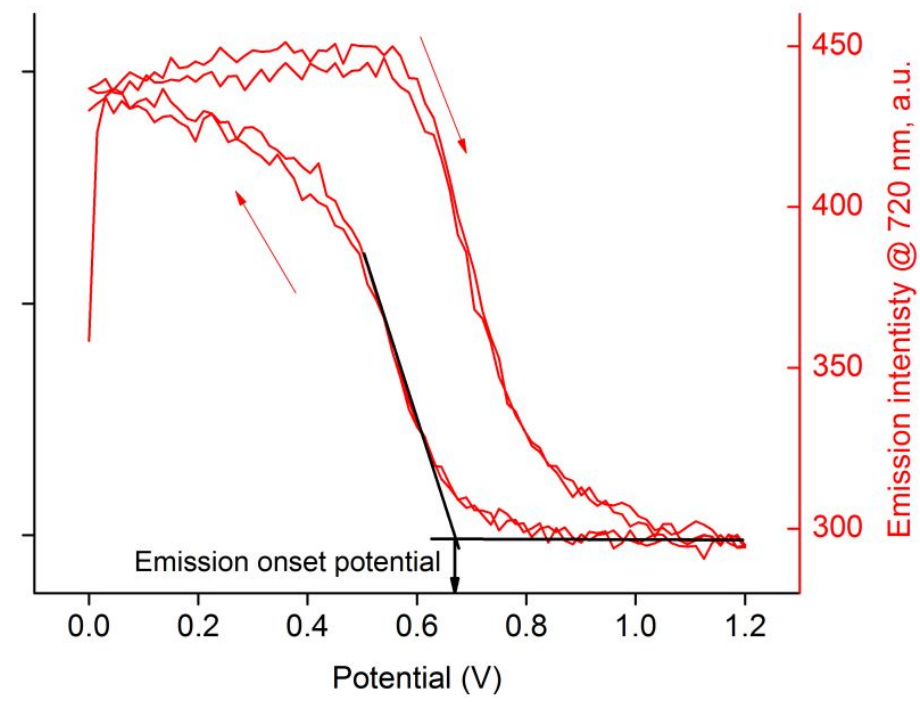

Figure S2. Graphical representation of emission increase onset potential, $\mathrm{E}_{\mathrm{EIO}}$, determination method, using emission vs applied potential dependence. 


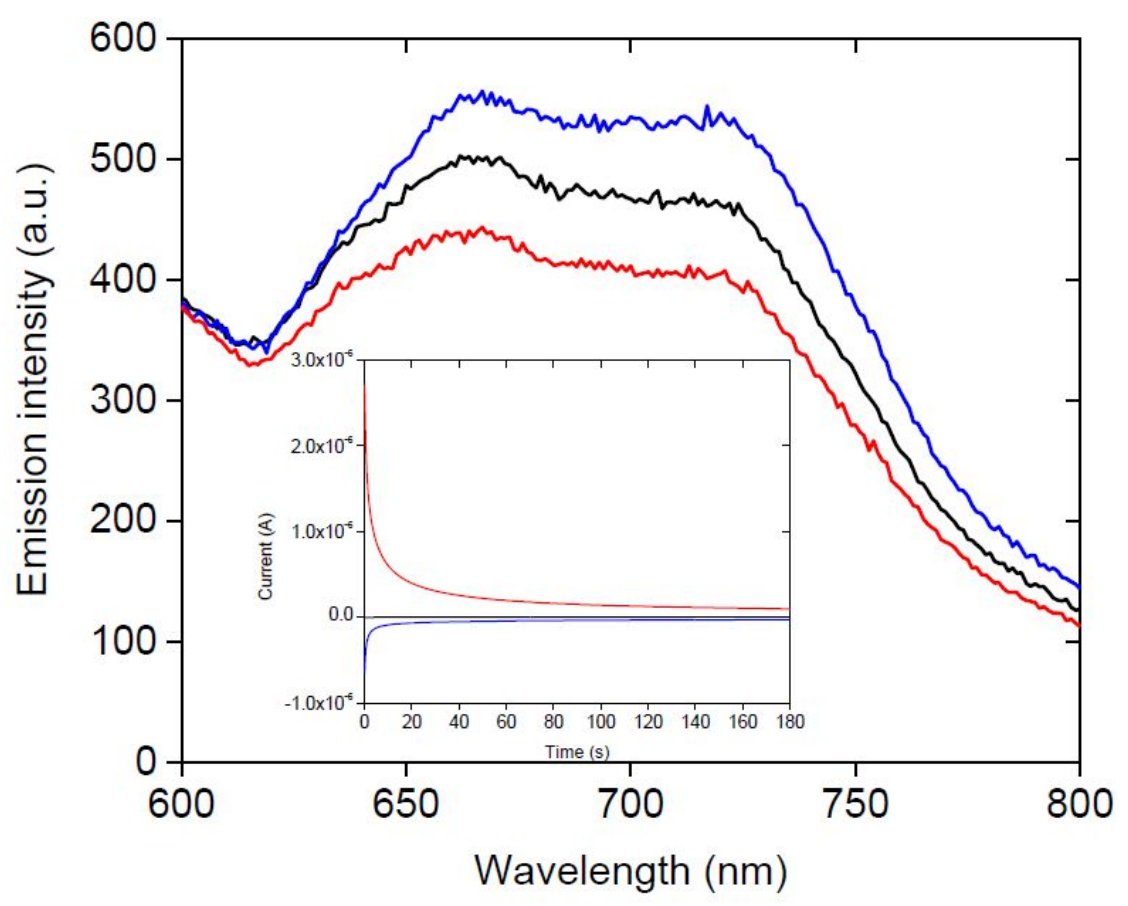

Figure S3. Emission spectra recorded for ion-selective membrane containing POT in $0.1 \mathrm{M}$ $\mathrm{KCl}$ recorded under (black line) open circuit conditions, as well as recorded while applying (red) oxidizing $(1.2 \mathrm{~V}) /$ (blue) reducing $(0.2 \mathrm{~V})$ potential for $120 \mathrm{~s}$ before and during emission scan. Inset: complementary chronoamperometric dependencies. 
A)

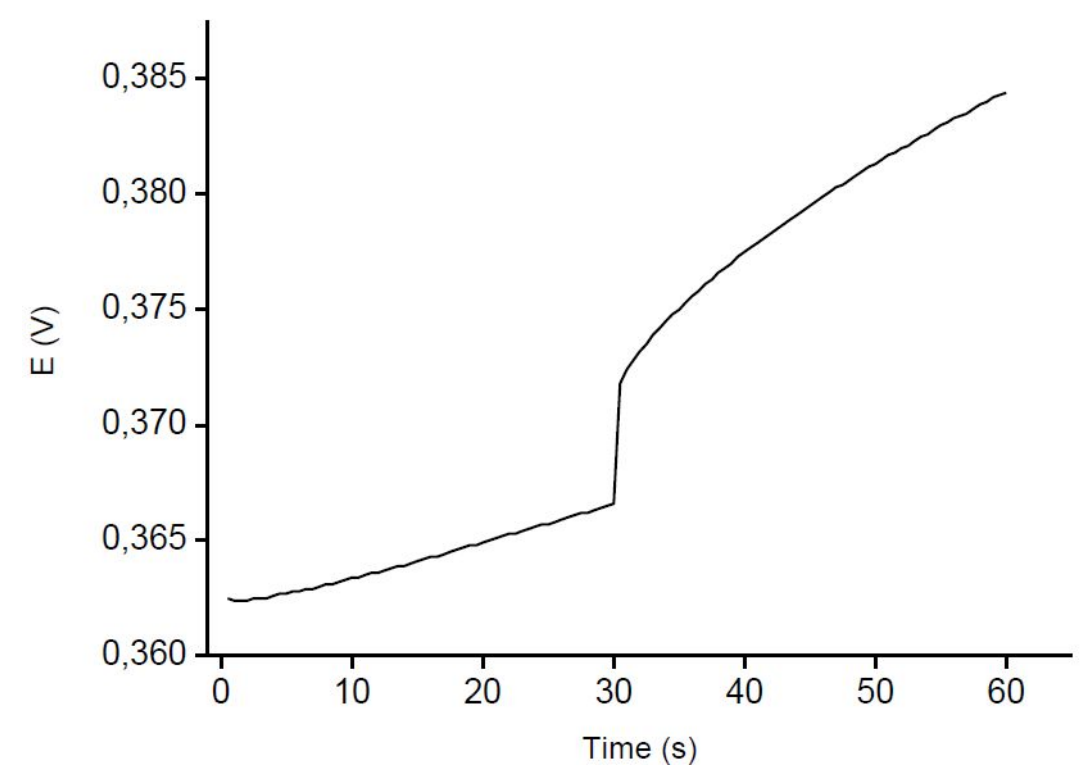

B)

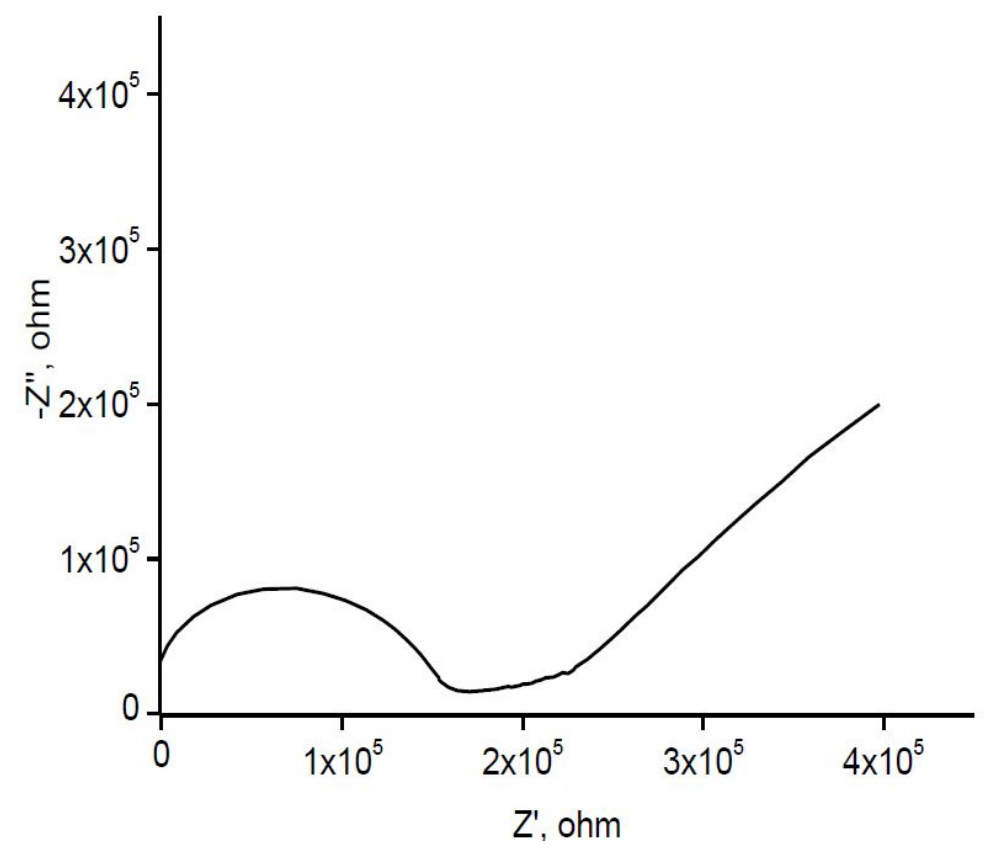


C)

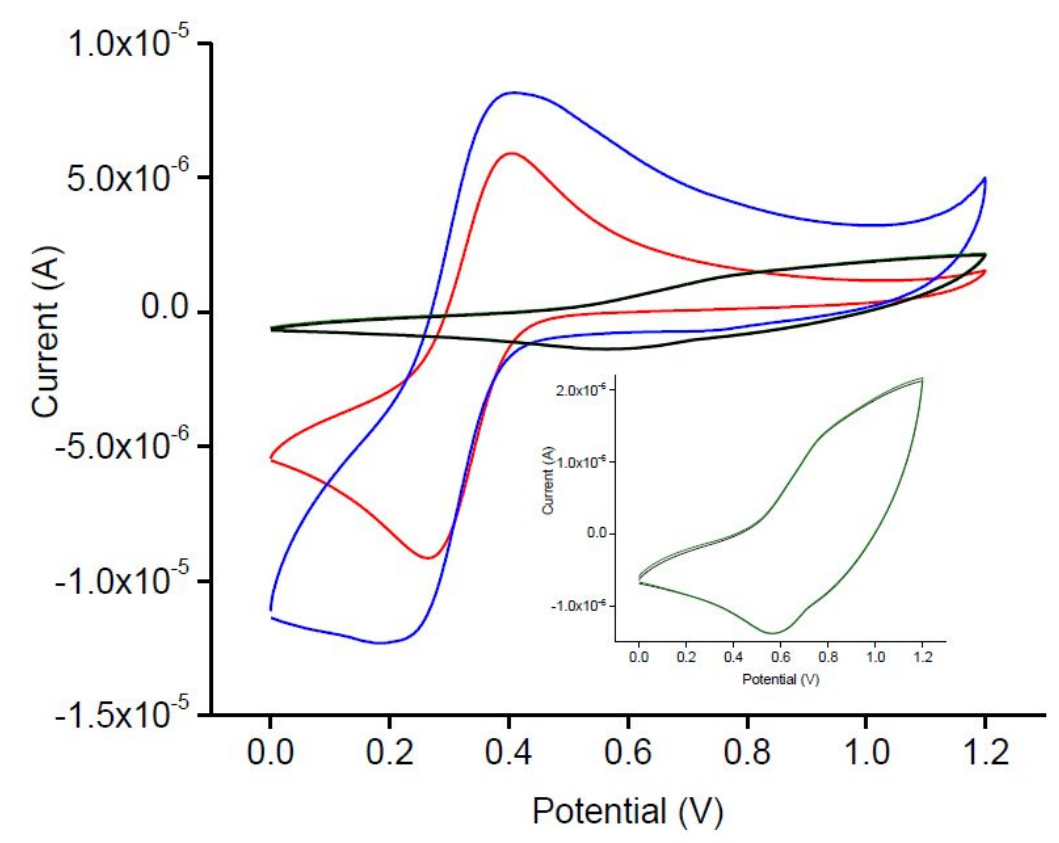

Figure S4. Electrochemical studies of FE-ISE membranes: A) Chronopotentiometry applying current equal to $1 \cdot 10^{-8} \mathrm{~A}$ in $0.1 \mathrm{M} \mathrm{KCl}, \mathrm{B}$ ) Impedance spectra of tested sensors recorded in 0.1 $\mathrm{M} \mathrm{KCl}$, at potential $0.3 \mathrm{~V}, \mathrm{C}$ ) cyclic voltammograms (scan rate $50 \mathrm{mV} / \mathrm{s}$ ) recorded for: (blue line) support (unmodified) carbon paper, (red line) glassy carbon electrode, (black line) as prepared sensors with carbon paper support and FE-ISE membrane in solution containing 10 $\mathrm{mM} \mathrm{K}_{4} \mathrm{Fe}(\mathrm{CN})_{6}$ in the presence of $0.1 \mathrm{M} \mathrm{KCl}$, for comparison trace recorded for as prepared sensors with carbon paper support and FE-ISE membrane in $0.1 \mathrm{M} \mathrm{KCl} \mathrm{-} \mathrm{in} \mathrm{the} \mathrm{absence} \mathrm{of}$ redox couple is also shown (green line) - this trace overlaps with the black line as shown on inset. 
A)

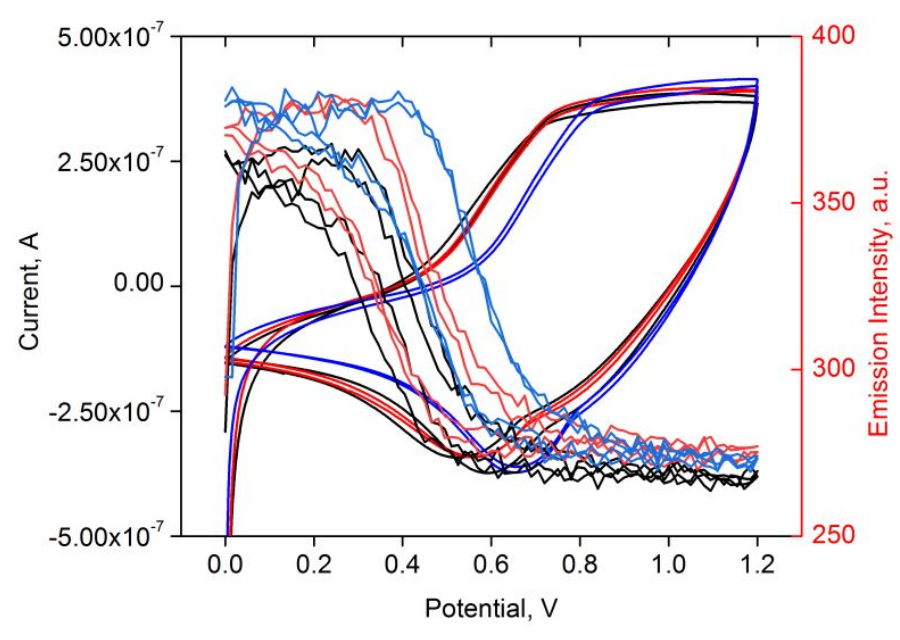

C)

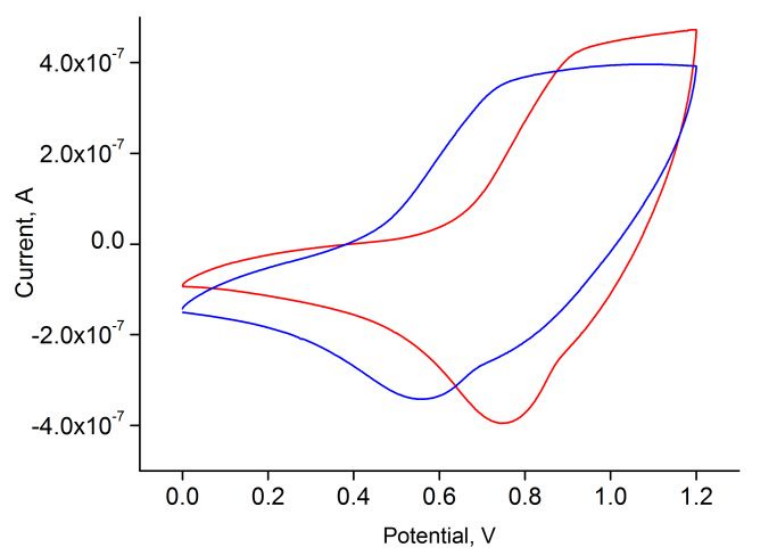

E)

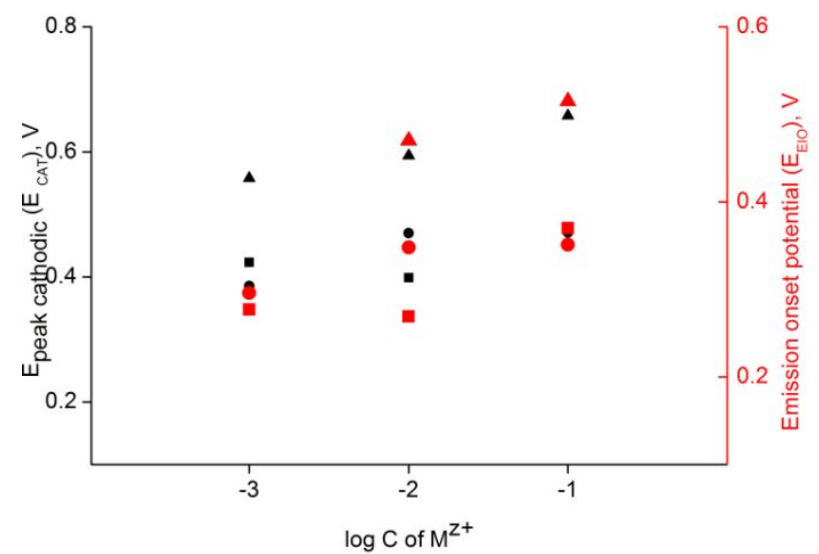

B)

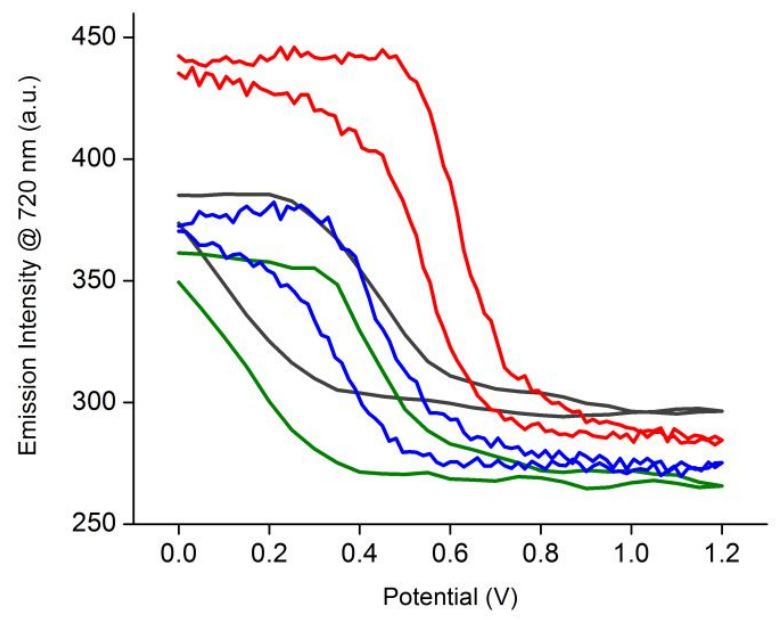

D)

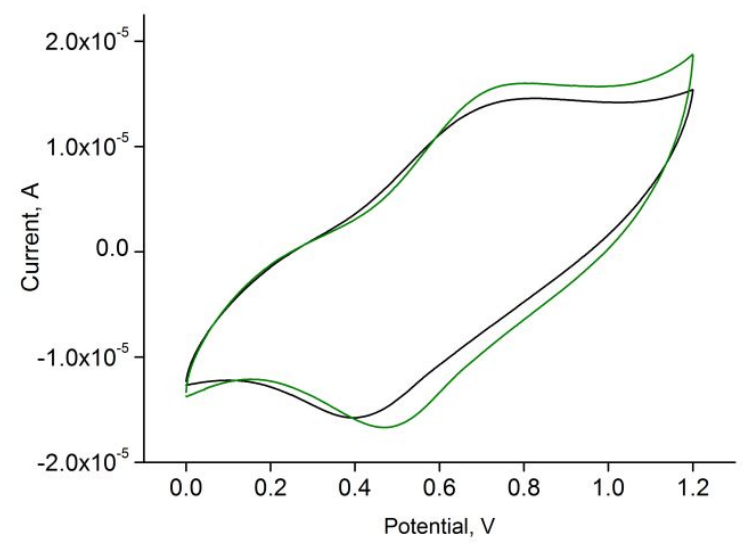

F)

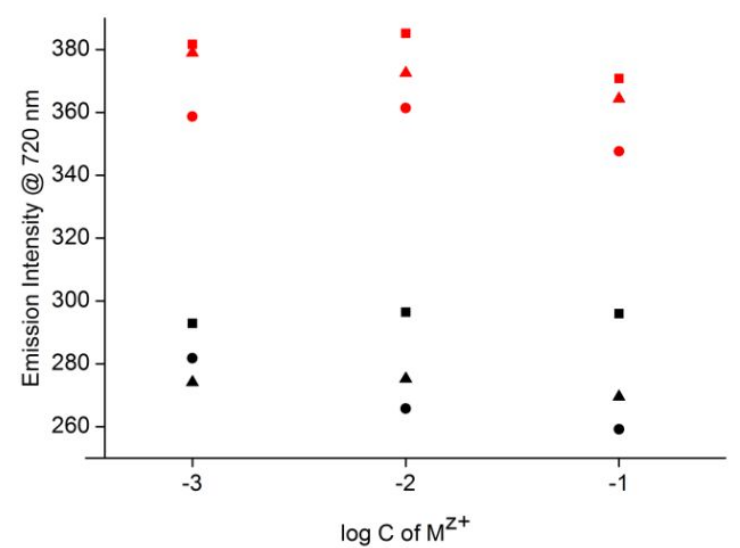

Figure S5. A) Cyclic voltammograms of (black) $10^{-1} \mathrm{M}$, (red) $10^{-2} \mathrm{M}$, (blue) $10^{-3} \mathrm{M}, 5 \mathrm{mV} / \mathrm{s}$ recorded in $\mathrm{NaCl}$ and emission read at $720 \mathrm{~nm}$ recorded during $\mathrm{CV}$ experiments. B) Emission 
changes recorded during and cyclic voltammograms experiments performed in $10^{-2} \mathrm{M}$ solutions of (red) $\mathrm{KCl}$, (black) $\mathrm{CaCl}_{2}$, (blue) $\mathrm{NaCl}$, (green) $\mathrm{MgCl}_{2}$ : B) scan rate $5 \mathrm{mV}$ for $\mathrm{KCl}$ an $\mathrm{NaCl}$, and C) $50 \mathrm{mV} / \mathrm{s}$ for $\mathrm{CaCl}_{2}$ and $\mathrm{MgCl}_{2}$. ), C) and D) cyclic voltammograms. E) Dependence of (black symbols) cathodic peak potential ( $\left.\mathrm{E}_{\mathrm{CAT}}\right)$ and (red symbols) emission onset potential ( $\mathrm{E}_{\mathrm{EIO}}$ ) on $\log \mathrm{C}$ of model interferents tested: $(\boldsymbol{\square} / \boldsymbol{\square}) \mathrm{CaCl}_{2},(\bullet / \bullet) \mathrm{MgCl}_{2},(\mathbf{\Delta} / \mathbf{\Delta})$ $\mathrm{NaCl}$. F) Dependence of emission recorded on logarithm of $(\boldsymbol{\square} / \mathbf{\square}) \mathrm{CaCl}_{2},(\bullet / \bullet) \mathrm{MgCl}_{2},(\boldsymbol{\Delta} / \mathbf{\Delta})$ $\mathrm{NaCl}$ concentration at (red symbols) $0 \mathrm{~V}$ and (black symbols) $1.2 \mathrm{~V}$. 